\title{
NEUROART
}

\section{Cefaleia e arte: ex-voto como arte da devoção e gratidão}

\author{
Headache and art: ex-voto as art of devotion and gratitude
}

\begin{abstract}
Moema Peisino Pereira, ${ }^{1}$ Luciana Patrízia A. Andrade-Valença, ${ }^{1,3}$ Amanda Araújo da Silva, Raimundo Silva-Néto, ${ }^{1}$ Louana C. Silva, ${ }^{7}$ Daniella Araújo de Oliveira, ${ }^{2}$ Hugo André de Lima Martins, ${ }^{7}$ Carlos Alberto Bordini, 4,5 Marcelo Moraes Valença ${ }^{1,3}$

'Unidade Funcional de Neurologia e Neurocirurgia, Departamento de Neuropsiquiatria, Universidade Federal de Pernambuco, Brasil ${ }^{2}$ Departamento de Fisioterapia, Universidade Federal de Pernambuco, Brasil ${ }^{3}$ Hospital Esperança, Recife Brasil ${ }^{4}$ Neurologia, Faculdade de Medicina Barão de Mauá, Ribeirão Preto, São Paulo, Brasil ${ }^{5}$ Clinica Neurológica Batatais, Batatais, São Paulo, Brasil

Pereira MP, Andrade-Valença LP, da Silva AA, Silva-Néto R, Silva LC, Oliveira DA, Martins HA, Bordini CA, Valença MM. Cefaleia e arte: ex-voto como arte da devoção e gratidáo. Headache Medicine. 2013;4(1):36-39
\end{abstract}

\begin{abstract}
RESUMO
Neste artigo, os autores revisam o uso do ex-voto como uma forma de arte para expressar devoção e gratidão. Ex-voto pode ser manifestado como objetos ou pinturas, como uma forma de ação de graças por uma oração respondida ou benção recebida. Muitos santos são invocados quando se está lidando com dores de cabeça incapacitantes, como São Denis, Santo Acacius, Santa Gemma e Santa Teresa de Ávila, além do uso de objetos de arte, incluindo esculturas e pinturas, que são produzidos comercialmente como base dessas práticas religiosas.
\end{abstract}

Palavras-chaves: Ex-voto; São Denis; Arte; Pintura; Religião.

\begin{abstract}
In this article the authors review the use of ex-vote as an art form expressing devotion and gratitude. Ex-voto may be manifested as objects or paintings, as a form of thanksgiving for an answered prayer or a blessing received. Several saints are invoked when one is dealing with incapacitating headaches, such as St. Denis, St. Acacius, Saint Gemma and St. Teresa of Avila. Objects of art, including sculptures or paintings, are commercially produced on the basis of these religious practices.
\end{abstract}

Keywords: Ex-voto; St. Denis; Art; Painting; Religion.

\section{INTRODUÇÃO}

O ex-voto é uma manifestação artístico-religiosa que desperta crescente interesse de historiadores, arqueólogos, antropólogos, médicos e colecionadores. $\bigcirc$ termo exvoto é a abreviatura de ex-voto suscepto - ou voto realizado e as palavras "votivo, votiva" vêm de votum (desejo), donde deriva também "devoção". Uma oferenda "votiva" é um dom que se faz como homenagem, desejo ou cumprimento de graça alcançada à alguma divindade. ${ }^{(1,2)}$

A prática votiva apresenta três etapas: realização do voto, manifestação do milagre e pagamento da promessa na forma uma pintura, escultura, fotografia, placa, carta, bilhete, peça de vestuário, fios de cabelos e órteses, entre outros, fazendo referência peculiar ao sofrimento subido e graça alcançada. ${ }^{(3-5)}$

Os ex-votos são uma "fé-pública", e não silenciosa. Servem como testemunhos para outros fieis, reforçam a devoção e credibilidade de um determinado Santo. São expostos em recintos denominados "salas de milagres" ou "salas de promessas" de templos sagrados, centros de romarias e de peregrinações. ${ }^{(1,6)}$ Atualmente, até a internet é local de divulgação de ex-votos, havendo endereços eletrônicos especializados. ${ }^{(7)}$ 
A arte votiva brasileira, mais especificamente a da região nordeste do Brasil, tem grande representatividade no animismo - herança da cultura africana. As esculturas são confeccionadas com traços retos e formas geométricas, triangulares e retangulares. ${ }^{(1,8)}$

Do ponto de vista artístico-estético, este gênero tem características marcantes da arte popular, destacandose o anonimato, o tom sentimental e simbólico das obras e a simplificação de cores, volumes e formas. ${ }^{(1,9)} \mathrm{A}$ preocupação formal com a técnica está em segundo plano, e grande parte dos artistas conhecidos como "santeiros" ou "milagreiros" são artesãos locais com acesso restrito a tradicionais escolas de arte.(1) Entretanto, há exceções, com artistas que obtiveram sucesso e obras clássicas com rigor à norma estética, como por exemplo a Madonnna di Foligno de Raffaello Sanzio (Figura 1).

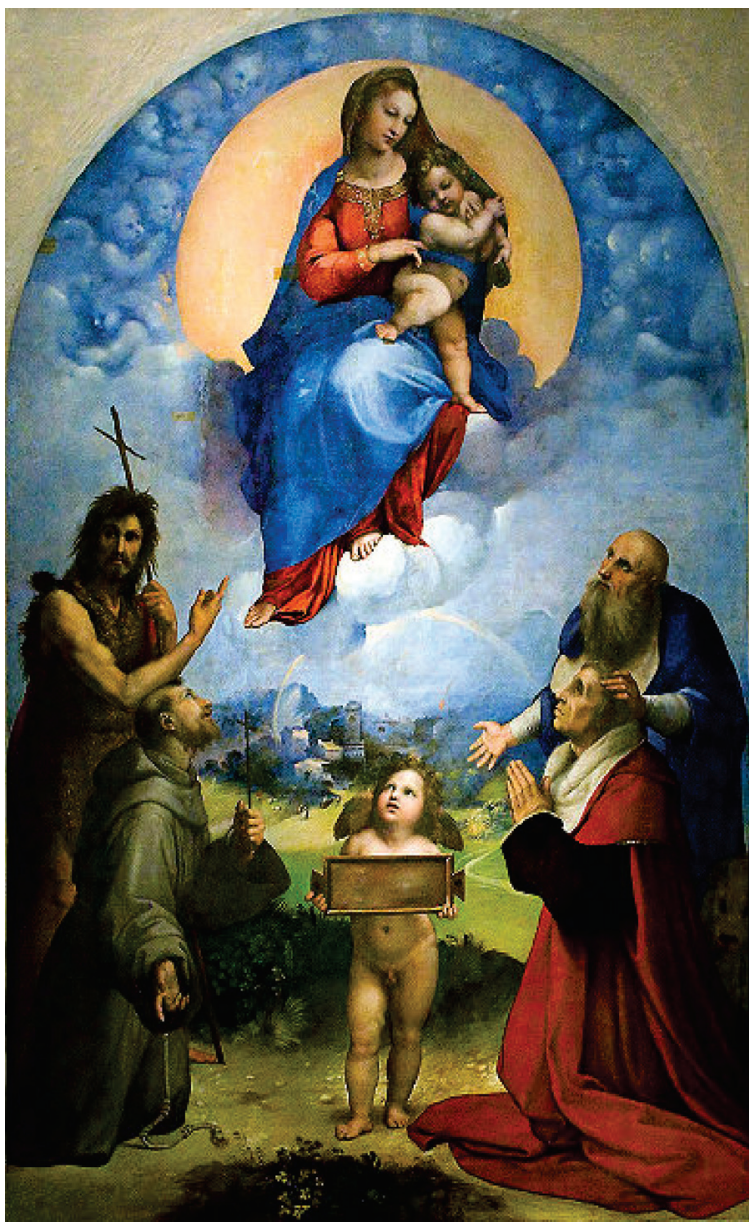

Figura 1. Madonnna di Foligno de Raffaello Sanzio. Esta pintura (1511-1512) foi uma encomenda de Sigismondo de' Conti, secretário do papa Júlio II, para comemorar um milagre por sua casa ter sido preservada após ter sido atingida por um raio. Note que na parte superior do quadro se pode perceber o formato de um encéfalo (perfil direito). Curioso é o fato de Michelangelo ter pintado o afresco "A Criação de Adão" em 1511-1512 (Capela Sistina, Roma), onde também se percebe imagem de um encéfalo (perfil esquerdo)

\section{EX-VOTO ANATÔMICO}

Quando o ex-voto é esculpido em formato de parte do corpo humano - cabeça, perna, braço ou órgao interno - é denominado "ex-voto anatômico".(10) $\mathrm{Na}$ Figura 2 três esculturas representando cabeças humanas são apresentadas. Notamos que diferem entre si em seus traços fisionômicos e penteados. Não sabemos ao certo se representam o fenótipo dos contemplados na ação de graças ou se foram comissionadas a São Denis ou Santo Acácio - santos protetores contra cefaleia, ${ }^{(10)}$ mas são arte e, como tal, segundo Pablo Picasso, uma mentira que nos faz perceber a realidade.

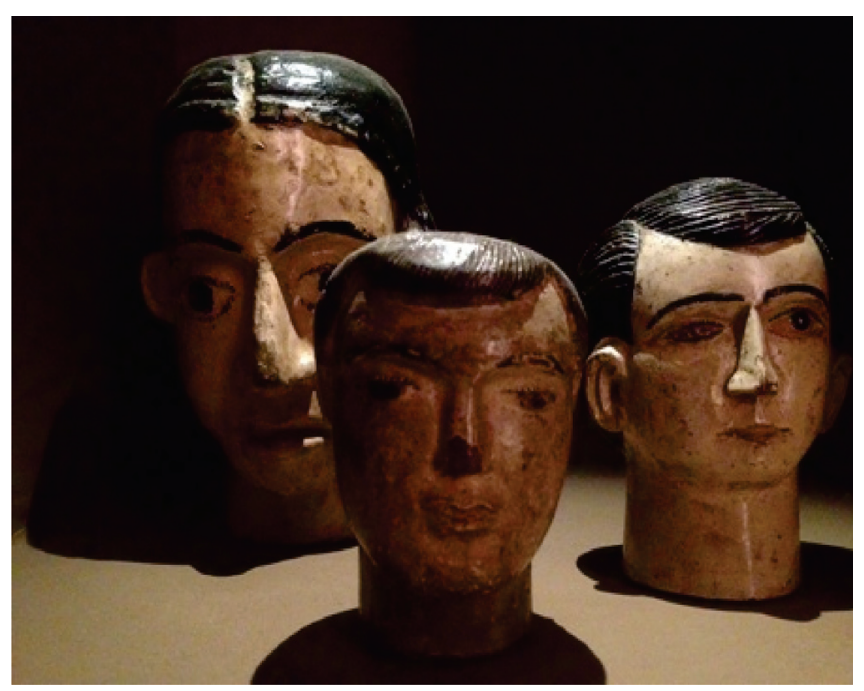

Figura 2. Ex-votos cefálicos anônimos esculpidos em madeira. Exposiçao no Museu do homem do Nordeste-Fundação Joaquim Nabuco, Recife, Brasil.

\section{SÃO DENIS, SÃO ACÁCIO E OUTROS SANTOS INVOCADOS PARA CURAR CEFALEIA}

São Denis foi o primeiro bispo de Paris e mártir da igreja católica. Foi perseguido e em 258 d.C. foi decapitado no Montemartre (monte do mártir, em referência ao martírio de São Denis). Diz a lenda que, após ser decapitado, São Denis levantou-se e segurando sua cabeça caminhou $10 \mathrm{~km}$ até sua igreja (hoje Basílica de Saint-Denis), onde morreu e foi sepultado. São Denis é invocado para a cura da cefaleia e é um dos Catorzes Santos Auxiliares (The Fourteen Holy Helpers) cujo culto surgiu no século XIV em local hoje pertencente à Alemanha, vinculado com a epidemia da peste negra. (11)

Esses 14 santos são venerados pela Igreja Católica por se acreditar que podem ajudar na cura de várias doenças. São eles: São Denis e São Acácio (ambos contra 
dores e males da cabeça), São Vito (contra epilepsia), São Pantaleão (contra o câncer e a tuberculose, e pelos médicos), Santa Margarida de Antióquia (contra os ataques diabólicos e um bom parto), Santo Egídio (contra a praga), São Jorge (em prol da saúde dos animais domésticos), Santo Eustáquio (contra a discórdia familiar), Santo Erasmo (contra doenças do ventre, intestinos e dores no parto), São Cristóvão (contra a peste bubônica), Santa Catarina de Alexandria (contra morte súbita), São Brás (contra doenças da garganta), São Ciríaco (contra a tentação no leito da morte) e Santa Bárbara (contra febre e morte súbita). Como cada um tinha uma "especialidade" ou incumbência especial todos juntos podiam combater uma doença grave em toda sua plenitude, com seus sintomas e manifestações. Essa incumbência foi determinada na Idade Média de acordo com a lenda ou martírio relacionada ao respectivo santo. ${ }^{(1)}$

Esses poderes concedidos por Deus eram para afastar certos perigos, curar doenças específicas e patrocinar determinados ofícios. Muito interessante esse conceito de "especialidade médica" vinculada a cada um desses santos, algo que se desenvolveu somente muito tempo depois na Medicina moderna.

Muitas vezes se usa uma oração para invocar esses santos, como a que se encontra a seguir:

\section{Oração aos Catorze Santos Auxiliares:}

"Deus todo poderoso e misericordioso, que honrastes com privilégios especiais vossos eleitos Jorge, Brás, Erasmo, Pantaleão, Guido, Cristóvão, Dinis, Ciríaco, Acácio, Eustáquio, Gil, Margarida, Catarina e Bárbara, dignai-vos conceder a todos os que, em suas necessidades, implorarem o socorro desses santos, a graça de serem atendidos em vista da salvação eterna. Por Nosso Senhor Jesus Cristo, vosso Filho, que convosco vive e reina na unidade do Espírito Santo. Amém."

Outros recomendam: "Mergulhar uma fita branca em água da chuva, e colocar no meio algumas pétalas de cravo, um pouco de alho esmagado e uma pitada de canela em pó. A fita deve ser amarrada ao redor da cabeça e se fala a oração abaixo":

"Bem-aventurado São Denis,

Por favor, interceda em meu nome com o Senhor para curar essa dor de cabeça, que está sobrecarregando meu espírito, para que eu possa também ser, como se estivesse em seu martírio, claro em meus pensamentos e ser capaz de venerar nosso Senhor. Amém".
Quando a cefaleia for curada, a fita, o alho e a canela devem ser mantidos por três dias. A fita pode ser jogada fora, mas o alho deve ser preservado em água pura e envolto em um saquinho verde ou pano. Esse servirá como amuleto para evitar futuras dores de cabeça.

Santo Acácio (que também é conhecido por Agathius, Achatius, Acacius) foi um centurião romano natural da Capadócia que foi também decapitado. $\mathrm{Na}$ Idade Média, Santo Acácio foi muito popular na Europa, e the é atribuído o poder de curar dores de cabeça. Gilberto Freyre refere que Santo Acácio já era invocado em Pernambuco no século XVI por pessoas que sofriam de cefaleia. ${ }^{(11)}$

Santo Avertinus, Santo Atazano, Santa Catarina de Siena e Santa Teresa de Ávila também são santos para os quais orações são oferecidas para receber uma graça de cura de uma dor de cabeça.

Outra santa invocada contra cefaleia é Santa Bibiana. Com a morte de seus pais, a órfã Bibiana foi aliciada para ser prostituta e, com a sua recusa, Bibiana foi presa e torturada até a morte a chibatadas por não ceder. Aqueles que a tocavam, de acordo com a lenda, eram acometidos de loucura. Por conta disso, ela foi transferida para um hospício, onde os doentes se curavam. Tendo morrido em 361 d.C., seus restos mortais foram lançados aos cães numa rua de Roma. No entanto, eles não encostaram em seu corpo. No local onde o corpo de Santa Bibiana foi enterrado floresceu um belo jardim onde ervas eram colhidas para curar diversas doenças, como dor de cabeça e epilepsia. Nesse local foi construída a Igreja de Santa Bibiana.

Outros santos que supostamente podem curar outros tipos de dor ou condições vinculadas a manifestação dolorosa, são: São Madron (contra dor), Santa Apolônia (contra dor de dente), São Policarpo (contra dor de ouvido), São Wolfgang (contra dor de estômago), São Bernardo (contra dor na coluna), Santa Amélia (contra doenças dos braços), São João de Deus (contra doenças do coração), Santa Juliana Falconiere e São Brice (contra doenças do estômago), São Aldegundo e São Pharaildis (contra doenças da infância) e São Lorenzo (Doenças das juntas). (12)

Ainda outra santa da Igreja Católica que é frequentemente invocada para interceder na cura de cefaleia é Gemma Galgani (Maria Humberta Pia Galgani).(13) Santa Gemma tinha fortes crises de cefaleia que se iniciavam na quinta-feira e cediam na tarde da sexta-feira, ocasião que falava receber sobre a cabeça a coroa de espinho de Jesus. 
Concluímos que a prática do ex-voto vem se tornando uma forma de arte muito presente nos dias atuais Figuras 3 e 4.

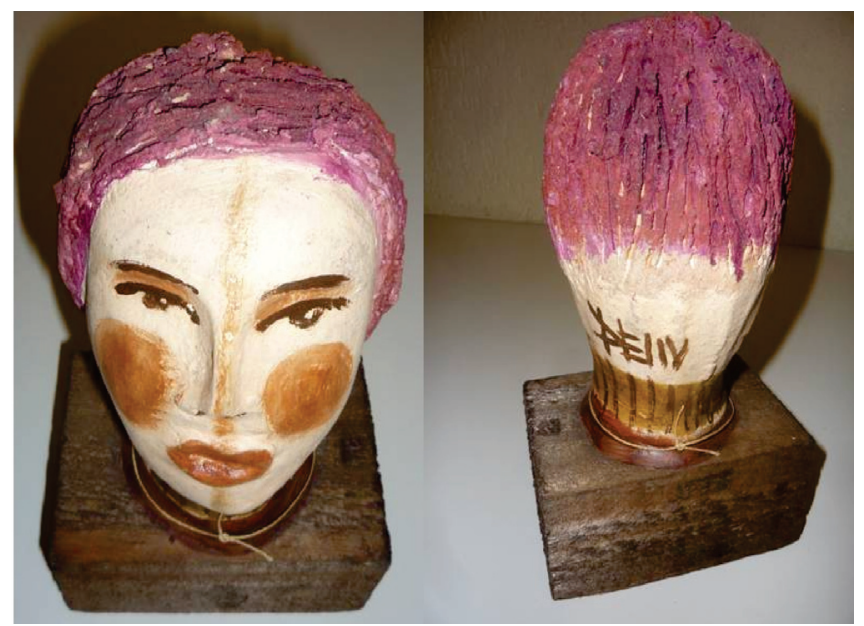

Figura 3. Ex-voto da ceramista pernambucana Delly Figueiredo.

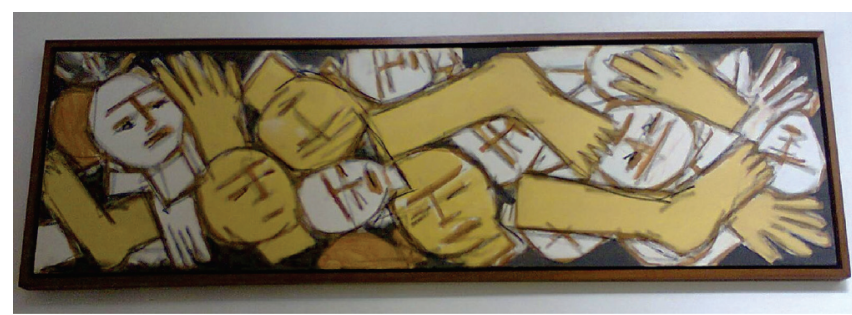

Figura 4. Quadro da artista plástica Ana Veloso com o tema ex-voto, onde se encontram varias imagens representando cabeças e membros.

\section{REFERÊNCIAS}

1. Duarte AHSD. Ex-votos e poiesis: representações simbólicas na fé e na arte. 2011397 f. Tese (Doutorado em História) Pontífica Universidade Católica, São Paulo.

2. Assumpção, I. Ex-voto, mídia das camadas populares. Disponível emhttp://www2.metodista.br/unesco/agora/ mapa_animadores_pesquisadores_lilian.pdf acesso em 01 de maio, 2013

3. Abreu JLN. Difusão, produção e consumo das imagens visuais: o caso dos ex-votos mineiros do século XVIII. Rev. Bras. Hist., São Paulo. 2005 ; 25(49).

4. Frade C. Santo de casa faz milagre: a devoção a Santa Perna. São José dos Campos, SP: Fundação Cultural Cassiano Ricardo, Centro de Estudos da Cultura Popular.

5. Teixeira IC, Cavalcante MM, Barreira KS, Aguiar AC, Gonçalves $\mathrm{SD}$, \& Aquino EC. $O$ corpo em estado de graça: ex-votos, testemunho e subjetividade. Psicologia \& Sociedade. (2010); 22(1): $121-9$.

6. Oliveira JCA. Ex-votos da sala de milagres do Santuário de Bom Jesus da lapa na Bahia: semiologia e simbolismo no patrimônio cultural. Revista Museu. 2006;1 (1):13-21.
7.Brunetti R. Gli ex voto. Disponível em http://www. riccardobrunetti.it/exvoto.htm acesso em 1 maio, 2013

8. Barros S. Arte, folclore e subdesenvolvimento ( $2^{a}$ ed.). Rio de Janeiro: Civilização Brasileira 1977

9. Leite RR. Arte e Religião: um estudo dos aspectos estéticos e religiosos dos ex-votos. Dissertaçao (Mestrado em Antropologia). Universidade Federal de Sergipe. São Cristovão 2012.

10. Neves GP. A arte de ser grato. Aparentemente toscas, as figuras ex-votivas revelam-se ricas em significados. Disponível em http:/ /www.revistadehistoria.com.br/secao/capa/a-arte-de-ser-grato, acesso em 30 de abril, 2013

11 . Andrade LE. Quartorze Santos de Emergencia. Objetiva, 2006. http://www.objetiva.com.br/arquivos/capas/85730281 14.pdf

12. http://www.idagospel.com/2013/04/7-perguntas-aoscatolicos-sobre-a-intercessao-dos-santos.html

13. http://pt.wikipedia.org/wiki/Gemma_Galgani

\section{Marcelo M. Valença.}

Neurology and Neurosurgery Unit, Department of Neuropsychiatry,

Federal University of Pernambuco, Cidade Universitária, 50670-420 - Recife, PE, Brazil Phone: +55 81 99229394; +55 8134263501 ;

Fax: +55 8121268539 mmvalenca@yahoo.com.br 